\title{
Age and Sexuality Online: Trends, Risks and Perspectives
}

\author{
Vladimir Kozlovskiy \\ The Sociological institute of the Russian Academy of \\ Science \\ Saint Petersburg State University \\ St. Petersburg, Russia \\ vvk_soc@mail.ru
}

\author{
Liliia Pankratova \\ Saint Petersburg State University \\ St. Petersburg, Russia \\ 1.s.pankratova@spbu.ru
}

\begin{abstract}
In this paper, we describe main trends in sociocultural practices, presentations, discussions and formation of sexualities by different age groups in cyberspace in modern information societies. The article examines performativity and embodiment of sexuality in online social spaces based on the results of an analytical research of social networks, social media and blogs data. The analysis is focused on the global and local characteristics of intersections between age and internet sexuality-virtual development and realization of intimacy, eroticism, sensuality and body.
\end{abstract}

Keywords-Cyberspace; Sexualities; Age group; Social network; Social media; Intimacy

\section{INTRODUCTION}

Sexuality is becoming increasingly popular object of study of scientists of the whole spectrum of scientific disciplines, including social sciences. Rising attention to the subject of sexuality is due to the latest trends and manifestations of public legitimization of various forms of sexuality, sexual behavior and attitudes, such as legalization of homosexuality in a number of countries in Western Europe. The variety of forms of sexuality, a significant diversification of value-regulatory complex in the area of sexual relations (from traditional to nontraditional liberal number of samples) stimulates the growth of public and scientific interest in the cultural aspects of sexuality. Modern metamorphosis of sexuality and the latter-day rivalry usual types of sexual culture lead to the transformation of the macro-level of social, family and household, political and economic spheres of life, the social structure of society and its institutions. In this article we try to analyze how cyberspace, as a specific arena for social communications, influence on formation of sexual behavior and sexualities development among representatives of different age groups.

Scientific and practical problems of the paper derive from the question: why the sexuality of different age groups is transferred from the offline to online space. Social and cultural practices radically change in the field of sexual relations. The essence of the changes that make up the main tendencies of modern societies is in such new contradictory phenomena as: personal autonomy, growing individualization and media programming of human behavior; private independence and intellectual localization in virtual space; displacement of real everyday relationships in favor of remote, artificial; the

The reported study was funded by RFBR according to the research project № 16-33-00020. transformation of direct communication with relatives, friends, partners in electronic communication. In other words, there is an expansion of online activity in all directions. Online resources have great advantages for different age groups. First of all, there are wide possibilities for choosing information resources, a variety of topics for individual needs, chances for inclusion in various communities. In the field of sexuality, online space gives its participants new tools for creative visualization, textualization, public discussion of issues of intimacy, corporality, eroticism. In addition, online offers much more suggestions in the search for partners for a romantic relationship. Geographical and cultural diversity of participants, new opportunities for communication and human relations are the basis for an endless search for a better partner, a variant of the device of private life. It is like an endless and unreachable movement toward the desired goal (finding a romantic partner, creating a family). Thus, in online relationships, there is the effect of virtual fetishization of sexuality, manifested, for example, in quasi-sexual objects: robots, pictures, sounds, graphics, as well as in the virtualization of sexual relations and actions.

\section{TOWARDS UNDERSTANDING OF SEXUALITY}

The phenomenon of sexuality is a complex for understanding and study aspect of human life. In search for answers about the essence of sexuality and specificity of sexual issues, people use diverse kinds of sources, including those available on the Internet, such as: books, articles, web sites, videos, etc. The Russian segment of the Internet contains psychological, biological, feminist, sexological, educational and other information on the issue. The great variety of existing interpretations of human sexuality in cyberspace that could be simultaneously found, on the one hand, expand the frameworks and enrich perception of this multidimensional phenomenon, but on the other hand, make evident contradictions in its understanding (e.g., essentialism vs. social constructionism), meaning and outcome for different social groups (LGBT communities, ethnicities, men and women, etc.).

Thus, representatives of different scientific fields try to capture sexuality's nature and implication on personal wellbeing. In contemporary science, sexuality is traditionally understood as a phenomenon that encompasses three main aspects: biological, psychological and socio-cultural. The first 
of these aspects is analyzed in the framework of biomedical research, the second - psychological and pedagogical, and the third - social and cultural studies. According to Igor Kon [1] together they form an equilateral triangle which allows seeing the sexual side of life in all its fullness and diversity. Therefore, a variety of theoretical approaches to the definition and nature of sexuality appeared. The most simple and common biological kind of interpretation considers sexuality as a source of sexual impulse, desire and sex satisfaction. A considerable amount of works used the term for a long time to refer only to sexual intercourse, "making love". This explanation actually denied sexuality of people who do not have sex, for example, accepted celibacy. That significantly narrowed the overall picture resulting in neglect of a variety of forms of sexual desire satisfaction.

Further interpretations of the sexuality concept indicate its relationship not only with the satisfaction of sexual desire, but also other needs (e.g., of psychic), such as strengthening the emotional and social relationships with other people [2]. "Sexuality in general is all those aspects of human constitution, and his / her behavior, which are associated with sexual activity. Some authors use the term in relation to love and deep affection, even if (more often) they are not related to the sex organs directly" [3]. Explanations of sexuality in terms of social constructionism with focus on gender and sexual identity are in demand not only in scientific discourse, but within civil (and sexual) rights and feminist movement as well. According to it nature of sexuality is socially constructed (denies the essentialist idea of the sexual instinct). Sexuality is understood as the product of a specific socio-cultural discourse [4].

However mentioned kinds of human sexuality interpretations seem to us disconnected from each other and quite narrowed - often focused only at one of the above aspects of the study of human sexuality and its definition. The most common sexological definition of the sexuality concept reflects the versatility and complexity of this phenomenon presenting it as a "very bright phenomenon caused by objective and subjective aspects of intrapersonal and impersonal factors, including a combination of biological, psychological, social and cultural processes related to the manifestation and satisfaction of sexual function" [5]. Thus, such concept of sexuality focuses on sexual desire or instinct, leaving to the social and human researchers' investigation of social and cultural frames of expression of desire, processes and mechanisms of their formation, especially psychic states. The communication space of the Internet allows easily find them in open online (medical, philosophical, psychological, sociological, etc.) dictionaries and encyclopedias, educational, research, and information websites, specialized literature.

Apart from scientific discourses another institutionalized explanation of sexuality is virtually presented on popular web resources (Wikipedia), international / national organizations' and social projects' web pages, etc. Dominant and wide spread definition, for instance, is the one promoted by the World
Health Organization (WHO), which regards sexuality as "a central aspect of being human throughout life encompasses sex, gender identities and roles, sexual orientation, eroticism, pleasure, intimacy and reproduction. Sexuality is experienced and expressed in thoughts, fantasies, desires, beliefs, attitudes, values, behaviors, practices, roles and relationships. While sexuality can include all of these dimensions, not all of them are always experienced or expressed. Sexuality is influenced by the interaction of biological, psychological, social, economic, political, cultural, legal, historical, religious and spiritual factors" [6]. In contrast to previous definitions this is a wide one. It takes into account different issues (elements) connected with sexuality, but not clarify their interconnections between each other and not make transparent the structure of sexuality phenomenon.

From our point of view, the key question in understanding sexuality concerns conceptual distinguishing between biological sex, gender (social sex), and sexuality. In the frame of sociology, a considerable amount of work has been done to address this issue, but still quite often the boundaries between sex, gender and sexuality are blurred and confused. This is explained by a number of authors partly by ideological issues [5]. In this article we interpret "sex" as a biological sex. It is acknowledged sexual diversity, including the polarity of male and female, as well as the existence of an androgynous (hermaphroditic). Sexual behavior in its turn is interpreted as actions related to satisfaction of human sexual needs.

Meanwhile gender and social sex refers to social and cultural differences between the two biological sexes fixed in established social norms, regulations, and conduct samples for each of them. It is expressed in the expectations of men and women regarding their performance of the gender roles behavioral patterns, as well as specific features of personality masculine or feminine. Natural differences are used as a basis for constructing social qualities and fixing the social hierarchy and order. It should be considered that in contemporary societies in addition to traditional gender roles emerge and constructed new alternative ones, such as androgynous, transgender. The number of possible types of masculinity and femininity varies and increases in the context of modern pluralism of lifestyles, the transformation of the gender order and norms [7].

In attempt to develop and clarify the available explanations in scientific literature, we define sexuality as a complex of erotic and emotional aspects of the individual and social practices. Sexuality is considered as a set of such socio-cultural characteristics of an individual as intimacy, eroticism, sensuality (psychic states and emotions), and body that are closely connected and shaped, but not limited to or identical to sexual desire and its satisfaction. We understand sexuality as a personal trait that is closely linked with the "Self-concept" [8]. It is formed partly by external conditions and social factors, but also consciously constructed by the individual. 


\section{SEXUALITY AND Age InTERSECTIONS}

In the special sociological and psychological literature there are different classifications of periods of psycho-sexual development of the individual (from Z. Freud to contemporary researchers). Creating such kind of classifications is a complex task that causes much debate and discussion. According to one of the most widespread in the Russian psychology concept of the age sex of human [9] periods of psycho-sexual development of the individual goes through the following stages:

\section{1) Prenatal period (from conception to birth);}

2) Parapubertal period (from 0-1 to 5-7 years);

3) Prepubertal period (from 5-7 to 11-13 years);

4) Puberty period (from 11-13 to $15-18$ years);

5) Transition period (from $15-18$ to $25-30$ years);

6) Period of mature sexuality (25-30 to 50-55 years);

7) Involutional period (50-55 and 70 and older).

However, this interpretation of human sexual development here is reduced mainly to the physiological (somatic) features of development of the organism, and the unit of measurement becomes sexually active individual. Social and cultural conditions of human sexual conduct, human sexuality as a set of such personal traits as intimacy, eroticism and sensuality, are being underplayed in this classification.

In our opinion, the formation of sex culture and sexuality of a social group or individual in its behavioral, value and normative aspects is socio-cultural processes. A range of actors, agents both deliberately and unconsciously take part in it with the usage of a variety of social technologies and mechanisms (methods) under the influence of specific concrete historical factors. The transmission of sexual patterns and values involves the acquisition of knowledge, skills and understanding of sexual behavior. Interestingly, belonging to a particular age group, generation is one of the first criteria of the difference in the socio-cultural development of sexual and psycho-sexual development of the individual and the group. The second is due to the age characteristics of the physiological and psychological development, while the first is a result of the specifics of social experience, the inclusion in various social institutions and organizations, community, etc.

\section{SeXuality AND Age in CyBerspace}

The topic of sexuality is increasingly promoted in the Internet space. Sexuality of different age cohorts thematically and in different information clusters has a trend of significant growth under the influence of two factors: 1) presentation in the virtual space of the consumption society and 2) expansion of the communicative space of manifestation, realization of sexuality, eroticism. On the one hand, the consumer society requires demonstrative sexuality. On the other hand, in cyberspace, there are opportunities to present different models and styles of sexuality. There is individualization of sexuality, namely, it is possible to demonstrate one's own habits, manners in cyberspace. Sexuality, sexual attraction is often considered to be a mystery, then internet allows to remove this magical power of sexuality. But as we explained above, sexuality is not reducible to the sexual and gender aspects, but it is a broader area of psycho-emotional closeness and intimacy. A number of close people from the erotic side, bodily attractiveness, connectedness (intimacy) with this person are demonstrated online. Cyberspace is confirmed by the concept of augmented reality, but in the sphere of sexuality it receives the most vivid manifestation. Such factor as the effect of imaginary anonymity pushes users to search not only educational topics about sexuality, but also deviant forms of sexuality, satisfaction of curiosity; another factor is availability of information materials and freedom of discussion in cyberspace, so this is an addition to real life, which is largely tabooed, regulated in this area. This provokes the use of virtual space to satisfy curiosity. Social networks, in this sense, prove the values of liberalism, the emancipation of sexuality.

Another social need is the search for your community, networks of like-minded people, the same curious ones, and also the "age" community. The aspect of sexuality in virtual form is the concentrated search for one's social group, the network, for your own identity. Discourses of sexuality of different age groups in the Internet space come into contact with each other. In real life intergenerational discussions of sexuality are rare. The Internet is a meeting place, collision, discussion of different representations, behavior patterns. Cyberspace is a storehouse of ideas about sexual life. But in social networks, not only the technical side of sexual life, but also the side of sensuality, intimacy, are reflected. We may talk about virtual sublimation of sexuality in the digital age.

Table I, based on quires on "Google" web search engine, reflects the range of sexual activities on the Internet of representatives of different age groups: sexual education, information retrieval; search for sexual and romantic partners; merchandise of sex goods; cybersex; body modification, etc. According to various studies [10,11], there is diversity in sexual practices on the Internet in various groups that differ in terms of socio-demographic characteristics. Thus, it was found out that young people frequently use Internet in different spheres of their everyday life, including sexual one (search for sex/intimate partners, watching pornography, etc.), while elder users seem less comfortable with online sexual activities [12]. Nevertheless, online sexual activities are also highly associated with risk behaviors. Finding partners in the Internet does not protect from unsafe sex, concurrent partnership, and threats to sexual health [13]; as well as dangers to psychological heath like cybersex addiction [14]; and negative social outcomes from online sexual bulling and harassment in almost any age.

The most frequently in contemporary science are studied specific age groups, generations. Mainly online sexuality studies are devoted to young people, students, and urban citizens. There is a lack of research on sexual activity in the cyberspace of different age groups (e.g., elder ones), as well as longitudinal and / or biographical studies that allow to trace the influence of using the Internet for sexual purposes on the formation, change of sexual scenarios [15] of people, on their sexual and romantic, marriage and family life in general for the last several decades. Moreover, the empirical research on internet sexuality is mostly conducted in specific regions (cities, 
countries, primary western), and there are no findings on global sexual activities in cyberspace of different socio-demographic groups. That often does not allow assuming any evident-based conclusions on the influence of the Internet on sexual sphere of life worldwide or in comparison of various regions.

TABLE I. Top SEARCH “SeXuality” Terms In GoOgle SEARCH

\begin{tabular}{|l|l|}
\hline \multirow{2}{*}{ Group Name } & \multicolumn{1}{c|}{ Search Terms } \\
\hline \multirow{4}{*}{ Human sexuality } & \\
\hline \multirow{4}{*}{ Sexualization of men and women } & Sexuality test \\
\cline { 2 - 2 } & Female sexuality \\
\cline { 2 - 2 } & Women's sexuality \\
\cline { 2 - 2 } & Sexiest woman \\
\cline { 2 - 2 } Sexual relations and behavior & Sexy guy \\
\cline { 2 - 2 } & Sexy lingerie \\
\hline \multirow{2}{*}{ Sexual deviance } & Sexual compatibility horoscope \\
\cline { 2 - 2 } & First sexual experience \\
\hline \multirow{2}{*}{ Sexual art and culture } & Sex maniac \\
\cline { 2 - 2 } & Sexual harassment \\
\hline \multirow{2}{*}{ Sexualized body } & Sexy movie \\
\cline { 2 - 2 } & Sexy video \\
\cline { 2 - 2 } & Sexy dance \\
\hline
\end{tabular}

\section{CONCLUSION}

Cyberspace plays one of the key roles in formation and exposure of patterns of sexual conduct, transmission of erotic values and norms. Cyberspace becomes a public and almost unlimited (except for some law restrictions) resource for development of an individual's sexuality. The Internet is a social agent of sexual education and knowledge dissemination, resource of construction of personal (private) intimate behavioral path and sexual trajectories, space for erotic and romantic entertainment. These are common trends and opportunities for the Internet users despite their age, ethnicity and sex, because of such characteristics of cyberspace as depersonification, anonymity, global access, and the culture of real virtuality [16]. New information and communication technologies and devices available to an ever-wider range of users allow creating augmented reality of the human sexual world. In particular, in various social networks, Facebook, Youtube, Instagram, Vkontakte, new discursive fields are formed in individual and group blogs devoted to the subject of body, body care, sexual health, sexual behavior, new sexual and gender communities. At the same time, sexual topics are actively exploited for commercial purposes, in the promotion of pornography, pedophilia. Therefore, cyber resources are potentially and actually used in completely different interests. Identified features of cyberspace as a new socio-cultural resource impose limitations on deeper study of online space and extraction of data from it that are necessary for understanding various social and cultural processes. One of that limits is determined by the lack of freely available and trustful personal information about users, such as age or sex. To derive precise and comprehensive information about sexualities of different age groups the "mixed strategy" applies the most: mixed methods strategy, as well as mixed objects (online and offline). That will allow not only to spot out the key tendencies in internet sexuality development (described above), but also to strongly correlate and expand the notion of them in regard with social and cultural specificity of different age groups intimacy, eroticism, and body understanding and practice.

\section{REFERENCES}

[1] I.S. Kon, Introduction to sexology [Vvedenie v seksologiyu]. Moscow: Medicina, 1989, pp. 3-4.

[2] E.V. Zajceva, Intergenerational dynamics of sexual culture: the sociological analysis [Mezhpokolencheskaya dinamika seksual'noj kul'tury: sociologicheskij analiz]. Doctoral thesis. Ekaterinburg: Ural State Technical UniversityUniversity, 2006, pp. 28-29.

[3] V.A. Zhmurov, Big Encyclopedia of psychiatry [Bol'shaya ehnciklopediya po psihiatrii]. Moscow: Dzhangar, 2012.

[4] M. Foucault, The history of sexuality. Volume 1: An Introduction. London: Allen Lane, 1979.

[5] E.A. Kashchenko, Basics of sociocultural sexology [Osnovy sociokul'turnoj seksologii]. Moscow: Book House Librokom, 2011, pp. 15-25.

[6] WHO, Defining sexual health: report of a technical consultation on sexual health, 28-31 January 2002. Geneva, World Health Organization, 2006.

[7] I.S. Kon, "Hegemonic masculinity as a factor in male (un)health" [Gegemonnaya maskulinnost' kak faktor muzhskogo (ne)zdorov'ya], in Andrology and Genital Surgery [Andrologiya i genital'naya hirurgiya], 2008, no. 4, pp. 5-12.

[8] A. Giddens, The transformation of intimacy: sexuality, love and eroticism in modern societies. Cambridge; Polity, 1992.

[9] G.S. Vasil'chenko, General sexual pathology [Obshchaya seksopatologiya]. Moscow: Medicina, 1977.

[10] K. Daneback, A. Cooper, S.-A. Månsson, “An internet study of cybersex participants," in Archives of Sexual Behavior, 2005, Vol. 34, no. 3, June 2005, pp. 321-328. DOI: 10.1007/s10508-005-3120-z

[11] D.S. Sienra, M. Palumbo, B. Zilli, H.F Sivo,. EROTICS Global survey 2017. Sexuality, rights and internet regulations. APC, 2017. Retrieved from https://www.apc.org/sites/default/files/Erotics_2_FIND-2.pdf

[12] K. Daneback, M.W. Ross, "The complexity of internet sexuality," in Sexual Dysfunction: Beyond the Brain- Body Connection, R. Balon, (ed). Adv Psychosom Med. Basel, Karger, 2011, vol 31, pp. 121-134.

[13] M. Cabecinha, C.H. Mercer, K. Gravningen, C. Aicken, K.G. Jones, C. Tanton, K. Wllings, P. Sonnenberg, N. Field, "Finding sexual partners online: prevalence and associations with sexual behaviour, STI diagnoses and other sexual health outcomes," in the British population In Sexually Transmitted Infections, 2017, Vol. 93, no. 8, pp. 572-582.

[14] F.-X. Poudat, M. Lagadec, "Cybersex addiction and cognitive behavioral therapy" [Cybersexualité addictive et thérapie comportementale et cognitive], in Journal de Therapie Comportementale et Cognitive, 2017, Vol. 27, no. 3, pp. 138-146.

[15] K. Daneback, Love and sexuality on the internet. Göteborg, 2006.

[16] M. Castells, The rise of the network society. Malden, Mass: Blackwell publishers, 1996, pp. 371-405. 